\title{
Experiência e família na literatura de Ana Castillo
}

\author{
Experience and Family in Ana Castillo's Literature
}

Thayse Madella' (iD 0000-0002-0954-6953

'Universidade Federal de Santa Catarina, Programa de Pós-Graduação em Inglês, Florianópolis, SC, Brasil. 88040-900-ppgi@contato.ufsc.br

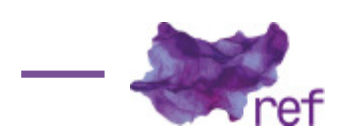

CASTILLO, Ana.

Black Dove: Mamá, Mi'jo and Me.

New York: The Feminist Press, 2016.

Nascida em Chicago, de família de descendência mexicana, a autora chicana' Ana Castillo aborda constantemente em suas obras - poemas, romances e ensaios - temas envolvendo questões de gênero, sexualidade, raça e etnia. Sua mais recente publicação, Black Dove: Mamá, Mi'jo and Me (2016), é uma coleção de ensaios autobiográficos sobre a história de sua família, desde seus avós até a sua experiência como mãe. Ao reconstituir essas histórias, a autora também remonta a relação fronteiriça e de poder entre os Estados Unidos e o México. Além de cruzar as fronteiras territoriais entre os países, a obra também cruza fronteiras: de linguagem, utilizando espanhol sempre que a língua inglesa se mostra insuficiente; de gêneros textuais, trazendo poemas, relatos históricos, e-mails e um ensaio escrito pelo seu filho, o artista chicano Marcello Castillo; e do tempo, debatendo tanto as experiências de seus antepassados, indígenas e mexicanos, junto com a de seu descendente para contar sua própria história. O livro é composto por 17 ensaios atravessados pela experiência de Castillo como uma mulher de cor, ${ }^{2}$ bissexual, de origem latinoamericana, vivendo em uma sociedade machista, branca, imperialista e hegemônica.

No atual contexto de imigração e xenofobia, ${ }^{3}$ historicizar a constituição da subjetividade de fronteira ganha contornos ainda mais importantes. Gloria Anzaldúa, em Borderlands/La Frontera:

\footnotetext{
$O$ termo "chicana" refere-se às mulheres de descendência mexicana que vivem nos Estados Unidos. Inicialmente usado de forma derrogatória, o termo foi apropriado pelo movimento chicano, na década de 1960, e hoje sinaliza o orgulho e consciência política de fazer parte de uma comunidade de cor constituída de códigos culturais distintos, e muitas vezes contraditórios, que constituem o sujeito de fronteira.

2 "Mulheres de cor" é um termo político de coalizão, usado por grupos marginalizados, nos Estados Unidos, que busca construir pontes entre diversas comunidades de mulheres não pertencentes ao grupo de mulheres brancas, descendentes de europeus. Diferentemente, no Brasil, a coalizão é formada em torno do termo "mulheres negras", mas como o contexto da obra e da autora aqui discutidos pertencem a uma autoidentificação como mulheres de cor, escolhi, neste trabalho, respeitar o uso político do termo. Para mais informações sobre o termo "mulheres de cor", ver ANZALDÚA, Gloria; MORAGA, Cherrie. This Bridge Called My Back: Writings by Radical Women of Color (1981). Bloomington: Third Woman Press, 2002.

${ }^{3}$ Nos Estados Unidos, as leis de imigração possuem, historicamente, contornos racistas e xenofóbicos, priorizando imigrantes europeus enquanto criminalizando grupos marginalizados, incluindo latino-americanos, principalmente mexicanos e muçulmanos, por exemplo (para mais informações sobre a relação entre preconceito e as leis de imigração dos Estados Unidos, ver o artigo: OPPENHEIMER, David; Prakash, Swati; Burns, Rachel Marie. "Playing the
} 
The New Mestiza (2007 [1987]), escreve: "A fronteira E.U.A.-México es una herida abierta em que o Terceiro Mundo range contra o primeiro e sangra"4 (Gloria ANZALDÚA, 2007, p. 3). É no sangrar do atrito entre as fronteiras que as histórias de Black Dove emergem. Já na introdução, o contexto dos e das imigrantes é apresentado: "Todos nós sabemos que este jovem e poderoso país em que nós vivemos foi construído literalmente no sangue, suor, e lágrimas de muitas pessoas de lugares e contextos históricos diferentes"5 (Ana CASTILLO, 2016, p. 3). A história da relação de poder entre México e EUA é o cenário do qual Castillo parte para contar a história de sua família. Até as primeiras décadas do século XX, o objetivo da patrulha na fronteira entre os dois países não era o de impedir a entrada de mexicanos ao norte. Isso passou a acontecer apenas depois da crise de 1929, quando a força de trabalho mexicana deixou de ser interessante para o rico país vizinho. Então, os imigrantes, junto com seus filhos nascidos nos EUA, foram repatriados como mexicanos. A ferida aberta da fronteira faz parte do contexto familiar da autora, posto que obriga a mãe de Castillo, nascida nos EUA, em uma família mexicana de classe média, a voltar para o México, aos sete anos de idade, e viver em condições de extrema pobreza (CASTILLO, 2016, p. 7-8). Este também é o contexto que faz sua mãe começar a trabalhar como empregada doméstica aos dez anos de idade e considerar a mudança para Chicago, onde trabalhou como funcionária no chão de fábrica e também como revendedora da Avon, o que resultou em um avanço na qualidade de vida da família.

Os primeiros ensaios de Black Dove focam nas histórias de sua mãe e de sua tia, Flora, tanto no México quanto nos EUA. A autora revisita as condições de sua família a partir de uma perspectiva feminista e consciente das relações de poder relativas a ser uma mulher de cor e da classe trabalhadora. Ao revisitar tais histórias, ela também as reescreve. O discurso da tia, por exemplo, ao descrever a experiência como costureira, trabalhando oito horas diárias em frente à máquina, lutando para alcançar a cota estabelecida pelo patrão, desenvolvendo uma série de doenças devido ao esforço repetitivo, é questionado: "Minha tia não usou a palavra 'love'. Ela disse 'encantada', o que em inglês significa 'enchanted' e que não poderia ter sido o que ela sentiu trabalhando oito horas diárias" (CASTILLO, 2016, p. 28). Quando a tia já aposentada relembra com carinho do trabalho cruel e desgastante, a autora precisa negociar as lembranças da tia através de uma perspectiva diferente. Castillo levanta dúvidas sobre a veracidade das palavras empregadas, fazendo com que a própria tradução para o inglês da expressão usada em espanhol também seja questionada. Dessa mesma forma, a tradição de comer e preparar tortillas é reescrita, relacionando a experiência de cozinhar um prato aparentemente tão corriqueiro e quase mecânico das famílias de origem mexicana ao laço afetivo construído com a mãe, figura frequentemente retratada como distante e pouco afetiva.

No ensaio "On Mothers, Lovers, and Other Rivals", a autora discute a constituição de sua (bis)sexualidade, tema atravessado com discussões como a militância LGBTT, o reconhecimento sobre o próprio corpo, a relação entre raça e sexualidade e a existência de mais de uma verdade para a mesma narrativa. Nesse ensaio, Castillo conta sua história de amor com a mulher por quem esteve apaixonada e o declínio do relacionamento. Ela ainda aponta para o fato de sua versão da história não ser a mesma da de sua ex-parceira. Como a autora trabalha numa constante relação envolvendo uma diversidade de tópicos, se torna difícil - para não dizer impossível pontuar um tema específico que circunscreva cada um dos ensaios. A história pode, inicialmente, parecer tratar sobre a paixão e o declínio de um casal, mas ganha contornos mais complexos ao questionar a noção de verdade ou ainda levantar as diferenças entre sexualidades não-normativas vividas por pessoas brancas e de cor. Dessa forma entrecruzada, não só seu filho e sua mãe se tornam parte daquilo que a constitui como sujeito, mas também sua relação com a mãe do exmarido, com um curandeiro na vila de Tepoztlán, no México, com seus alunos, alunas e com suas amantes, além de outros/as personagens que cruzam a vida da autora.

Trump Card: The Enduring Legacy of Racism in Immigration Law". Berkeley La Raza Law Journal, v. 26, n. 1, p. 1-45, 2016). No entanto, a eleição de Donald Trump para a presidência, em 2016, eleito usando uma plataforma antiimigração, racista e xenofóbica, reforça e autoriza ainda mais os preconceitos sofridos pelas comunidades de minoria tanto em níveis legais quanto discursivos (sobre Donald Trump como uma figura que incorpora o discurso da supremacia branca, racismo e xenofobia e o terror que essa presença causa nas comunidades marginalizadas, ler o artigo CASTRELLÓN, Liliana; RIVAROLA, Alonso Reyna; LÓPEZ, Gerardo. "We are not alternative facts: feeling, existing, and resisting in the era of Trump". International Journal of Qualitative Studies in Education, v. 30, n. 10, p. 936-945, 2017).

No Brasil, onde também temos um histórico de racismo e xenofobia, mesmo que em diferentes termos do processo estadunidense, a eleição de Jair Bolsonaro para a presidência também se deu sobre uma plataforma racista e preconceituosa. Aqui, campanhas como "O Sul é meu País" é um exemplo de xenofobia, que, para além dos imigrantes vindos de outros países, reforça o preconceito entre regiões dentro do próprio Brasil (mais informações sobre a xenofobia da campanha, ver dois artigos: CARDOSO, Felipe. "O sul não é meu país". Geledés, 2015. Disponível em: https://www.geledes.org.br/o-sul-nao-e-meu-pais/. Acesso em: 02/02/2019; COSTA, Viegas Fernandes. "O sul não é o meu país". Desacato, 2014. Disponível em: http://desacato.info/o-sul-nao-e-meu-pais/. Acesso em: 02/ 02/2019).

${ }^{4}$ Cf. tradução de COSTA, Cláudia de Lima; ÁVILA, Eliana. "Gloria Anzaldúa, a consciência mestiça e o 'feminismo da diferença'”. Revista Estudos Feministas, Florianópolis, v. 13, n. 3, set.-dez. 2005, p. 699.

${ }^{5}$ Tradução minha. Todas as traduções que aqui aparecem são minhas, exceto quando explicitado. 
Como mãe e feminista, Castillo também debate sobre as dificuldades de se criar um filho homem que não se encaixe nos papéis tradicionais de gênero e o impacto das relações sociais exteriores à casa nesse processo. Quando seu filho - a quem chama, na obra, de Mi'jo - frequenta a faculdade, ela o descreve da seguinte maneira: "Ele tinha consciência política. Ele entendia questões de raça e classe, especialmente em relação aos latino-americanos. No entanto, eu não tinha tanta certeza naquele momento se mujeres tinham feito tanto progresso desde a minha época como uma jovem ativista em Chicago" (CASTILLO, 2016, p. 139). A atitude do filho em relação ao posicionamento político que ocupa e o debate de gênero conversa com o movimento pelos direitos civis chicanos da década de 1960, quando a consciência política de raça e classe impulsionava a construção de uma comunidade ativista, la Raza, ao mesmo temo que oprimia e subjugava as mulheres. É nessa encruzilhada - entre lutar pela comunidade, contra o racismo e a exploração de classe, e defender os direitos e liberdades das mulheres - que as chicanas constroem seu próprio movimento. Mais especificamente, é desse complexo entrelaçamento de lutas que resulta a preocupação da autora em relação a seu filho. Castillo se considera como mãe rigorosa, preocupada com a educação e com o desenvolvimento de uma consciência política naquele sujeito de quem a criação é considerada sua responsabilidade - questão também criticada por ela ao afirmar sentir a pressão da sociedade sobre sua figura de mãe solteira com pouca ou nenhuma atuação por parte da figura paterna.

A maternidade cruza com a questão racial em diversos momentos, como na discussão sobre a prisão de seu filho. Ela tenta preencher as lacunas nas histórias para tentar compreender o ocorrido, reavaliando a criação e sua relação com o filho até o momento do crime que o deixou encarcerado por dois anos. Ela relembra vários casos de amigos e colegas de seu filho mortos ou presos e afirma, mais de uma vez, como um homem de cor, em uma comunidade latino-americana, está em contato com histórias de criminalidade e morte desde muito cedo. Da mesma forma, um episódio ocorrido semanas antes do encarceramento parece relacionar-se com a prisão. Quando um policial para o jovem rapaz em uma estrada, a possibilidade de ele ter cometido alguma infração ao volante é contraposta com o fato de uma pessoa de cor dirigindo (driving while brown ${ }^{6}$ ) ser suficiente para levantar suspeitas da polícia. Aparentemente sem relação uma com a outra, o encontro com a polícia e a eventual prisão de uma pessoa socialmente marginalizada, traça uma história de medo e descredibilidade nas figuras de autoridade e nas instituições. Ao cruzar a história do encarceramento com o encontro com a polícia, eventos aparentemente distintos são usados para tentar reconstituir um traçado na vida tanto do filho quanto de Castillo.

No livro, dois ensaios trabalham com materiais produzidos por Marcello Castillo. O primeiro, "What's in a nombre", com título emprestado da tradição shakespeareana, ganha tons latinoamericanos ao usar o termo em espanhol. Nesse texto, Marcello Castillo discute a importância da família e da comunidade latino-americana na construção da sua subjetividade ao contar como escolheu o seu nome artístico. Ao usar o sobrenome materno, "Castillo", não só homenageia a mãe como também reforça sua relação com a comunidade artística latino-americana, tornando o ato de se renomear em um ato político. Já o ensaio "Love, your son" traz a correspondência eletrônica entre mãe e filho durante os dois anos de encarceramento. Os e-mails apresentam as preocupações de ambos, o processo de reabilitação através da literatura e das discussões sobre arte, além do reconhecimento de ser ele também, como grafiteiro e poeta, artista e ativista político.

O processo de escrita é também um processo de constituição do sujeito. No caso da literatura chicana, e especificamente a de Black Dove, a construção da subjetividade é ainda uma forma de teorização sobre a própria chicanidade. Historicamente, chicanas foram silenciadas e apagadas pela perspectiva hegemônica do que significaria ser parte da comunidade. Escrever a própria história, da perspectiva de suas próprias experiências, então, se torna um ato de transgressão que requer um esforço constante em busca dessa subjetividade apagada da história oficial. Como escreve Cherríe Moraga, "eu estou diariamente buscando esses atos de rememoração de quem nós um dia fomos porque eu acredito que eles vão salvar nossos pueblos ${ }^{7}$ da extinção" (Cherríe MORAGA, 201 1 , p. 81). Escrever, então, se torna uma forma de sobrevivência. Assim, contar sua história permite a Ana Castillo relembrar e revisitar a história de sua família para construir e compreender seu próprio posicionamento nas fronteiras tanto geográficas como de sua subjetividade. Segundo Moraga, escrever é um ato coletivo e, se necessário, quem escreve "talvez tenha que emprestar ou inventar ao longo do caminho, mas temos o direito de lembrar. E eu não posso mais permitir que colonizador ou colonizado me diga que não" (MORAGA, 2011, p. 84). Em Black Dove, Castillo tenta fazer sentido das partes da história da qual não tem acesso direto com

\footnotetext{
${ }^{6}$ A expressão estadunidense, em inglês, refere-se ao fato da polícia parar e/ou multar latino-americanos na direção com maior frequência do que pessoas brancas. Refere-se também ao grau da penalidade aplicado a uma mesma infração cometida por uma pessoa de cor e por uma branca. Por exemplo, enquanto a primeira seria multada, a segunda ganharia apenas uma advertência.

${ }^{7}$ O termo estrangeiro na citação é mantido sem o uso do itálico em respeito às escolhas de escrita da autora, que não italiciza termos em espanhol por considerar que o uso "reflete uma sensibilidade bilíngue Chicana" (MORAGA, 2011 , p. xxii).
} 
as histórias vividas por ela mesma. Através da experiência coletiva da comunidade chicana, ela exerce o seu direito de lembrar quem é, de onde veio e de traçar caminhos alternativos daqueles previamente definidos para uma mulher de cor, latino-americana, que vive nos Estados Unidos.

\section{Referências}

ANZALDÚA, Gloria. Borderlands/La Frontera: The New Mestiza (1987). San Francisco: Aunt Lute, 2007.

CASTILLO, Ana. Black Dove: Mama, Mi'jo, and Me. New York: The Feminist Press, 2016.

MORAGA, Cherrie. A Xicana Codex of Changing Consciousness: Writings, 2000-2010. Durham: Duke University Press, 2011.

Thayse Madella (thaysemadella@gmail.com) é doutoranda no Programa de PósGraduação em Inglês (PPGI), na Universidade Federal de Santa Catarina (UFSC), com doutorado sanduíche financiado pela Fulbright (2019-2020), na Trinity University, em San Antonio, Texas, EUA. Atualmente, sua pesquisa trabalha com as relações entre desejo e sexualidade e as políticas de espaços fronteiriços na literatura Chicana. Possui mestrado em inglês também pelo PPGI.

\section{COMO CITAR ESSE ARTIGO DE ACORDO COM AS NORMAS DA REVISTA}

MADELLA, Thayse. "Experiência e família na literatura de Ana Castillo". Revista Estudos Feministas, Florianópolis, v. 28, n. 3, e67523, 2020.

\section{CONTRIBUIÇÃO DE AUTORIA}

Não se aplica.

\section{FINANCIAMENTO}

O presente trabalho foi realizado com apoio da Coordenação de Aperfeiçoamento de Pessoal de Nível Superior - Brasil (CAPES) - Código de Financiamento 001.

\section{CONSENTIMENTO DE USO DE IMAGEM}

Não se aplica.

\section{APROVAÇÃO DE COMITÊ DE ÉTICA EM PESQUISA}

Não se aplica.

\section{CONFLITO DE INTERESSES}

Não se aplica.

LICENÇA DE USO

Este artigo está licenciado sob a Licença Creative Commons CC-BY International. Com essa licença você pode compartilhar, adaptar, criar para qualquer fim, desde que atribua a autoria da obra.

\section{HISTÓRICO}

